\title{
Race and Inclusion in South African Education: Analysis of Black-African Learners' Perceptions in Previously Advantaged White Schools
}

\author{
TM Makoelle \\ University of Johannesburg \\ Email: tmakoelle@uj.ac.za
}

Doi:10.5901/mjss.2014.v5n14p283

\begin{abstract}
South Africa has adopted inclusive education system since 2001. The White Paper 6 was the first indication that inclusive education was to be implemented in schools. The implementation of inclusive education coincided with the political changes to de-racialize the population and bring national unity and cohesion. However South African remains one of the racially and ethnically divided nation in the world. This paper therefore analyses the role of race in relation to inclusive education. Critical Race Theory (CRT) and Critical Realism (CR) were used as lenses to understand the phenomena of race and inclusion. Interviews were conducted with selected black-African learners who attended school in previously advantaged white South African Secondary schools. An inductive analytical framework was used to understand the patterns and trends from the interview data. Among the findings is that while there have been policy shift towards inclusive education, exclusionary tendencies are still prevalent due to racially based attitudes in South African schools.
\end{abstract}

Keywords: Black learner, Critical Race Theory, Inclusion, Inclusive Education, Race, White learner.

\section{Introduction}

After 1994 South Africa adopted a new constitution (RSA, 1996) which contains the Bill of Rights (Makoelle 2012). South African society has undergone several changes since the dawn of its democracy in 1994. The education system, in particular, has undergone radical transformation. In 1997, the National Commission on Special Needs in Education and Training (NCSNET 1997) and the National Committee on Education Support Services (NCESS 1997) published a report on the quality of education for all, with special reference to overcoming the barriers to learning and development. The report constituted the first step in transforming the educational needs of all learners (NCSNET/NCESS 1997:1).

Historically, the South African education system has neglected the needs of the majority of learners, with the result that even special-needs education has not received the necessary attention (NCSNET/NCESS 1997). Consequently, it was crucial for the Department of Education to introduce inclusive education. Based on recommendations in the joint report (NCSNET/NCESS 1997), the department of education released the consultative White Paper 6 (2001) aimed at building an inclusive education and training system, which spelled out the commitment of the Department of Education to providing inclusive education that took into consideration the needs of all learners, especially those disadvantaged by the apartheid education system ( Makoelle 2012). The implementation of inclusive education in South Africa came amidst the process of phasing in an outcomes-based curriculum (OBE) which is based on the same assumptions as inclusive education; that is, on the belief that all learners can learn and succeed and that they have full control over their learning (Kruger 1998, Makoelle 2013).

South Africa, in its ambitious White Paper 6 (2001), conceptualises inclusive education among other things as

- being about changing attitudes, behaviour, teaching methodologies, curricula and the environment to meet the needs of all learners;

- maximising the participation of all learners in the culture and curricula of educational institutions and uncovering and minimising barriers to learning;

- empowering learners by developing their strengths and enabling them to participate critically in the process of learning.

The White paper 6 has its roots in the South African Constitution which according to articles 1(a) and 1(b) states that the Republic of South Africa (1993) is founded on among others, the following values:

- Human dignity, the achievement of equality and the advancement of human rights and freedoms.

- Non-racialism and sexism. These principles are reinforced in chapter 2 of the constitution, the Bill of Rights, 
which is relevant to this article. We should take special note of article 9(3) which declares that the state may not unfairly discrimination directly or indirectly against anyone on one or more grounds including race, gender, sex, pregnancy, marital status, ethnic or social origin, colour, sexual orientation, age, disability, religion, conscience, belief, culture, language and birth. Article 29(1) declares that everyone has the right to a basic education including adult basic education.

However despite all these significant policy pronouncements there have been silence on the inherent racial and ethnic divide which apparently perpetuates exclusive stereotypes and conceptions about those viewed as racially and ethnically different. There have been many reports about racial tendencies in South African schools. Among such reports, for example was the recent report in the South African media about one teacher who referred to black-African learners using the K-word (a derogative word used to refer to native blacks during apartheid era). The usage of the K-word was barred by the new democratic constitution of South Africa since 1993. The same teacher reportedly put a picture of one Black-African political leader next to the one of a baboon. This caused a stir and numerous complaints about the state of racial tolerance in some South African schools. The teacher has since been charged by the Department of Education. (Sowetan 2013). Therefore this and many other racial conundrums has prompted posing the following research questions:

To what extend does racial discrimination influence the implementation of inclusive education?

How can racial integration be enhanced in South African schools?

\section{Building a Theoretical Framework}

This paper adopts, firstly, Critical Race Theory (CRT) as a lens to understanding racial and ethnic dynamics of education in South African context. Delgado and Stefancic (2006) define CRT as a movement of a collection of activists and scholars interested in studying and transforming the relationship among race, racism and power. Ladson-Billing (1998, 2009) believes that race still matters in the education provision despite all global attempts to deal with the notion of racism in education. While there have been efforts to move away from racially based provision of education and embracing multi-racialism, race is still a dominant aspect used to determine how people relate to one another. While CRT was developed in the US and within the legal context, it has relevance to education particularly in a highly racial South African context. Ladson- Billing maintains that race is a cornerstone of exclusion as most discriminatory practices stem from the intention to subjugate other races. While there have been efforts to provide an equitable educational service to all races, racism manifests itself and continue to impact negatively to learners especially those that are black. For example according to Ladson-Billing aspects of schooling such as the school curriculum could be culturally specific artifact designed to maintain a cultural bias. While the work of Ladson-Billing and Tate (1995) were based in the context of the US, their use of CRT becomes more relevant within the South African context, as race was the basis on which the education system derived. There is an articulation that racism is endemic and deeply ingrained in human life and therefore needs to be looked at carefully.

Secondly, because the use of racism or racial discrimination might be implicit and hidden, it is crucial to unmask the underlying relational and causal mechanisms determining the use of racial undertones to exclude. In this case Critical realism (CR) was employed as a lens to magnify the racial practices. According to Roy Basker (1998) CR assumes that reality is layered and is constituted by three different domains, which are:

- Real: generative structures or causal mechanisms

- Actual: events resulting from various real tendencies and countertendencies in specific initial conditions

- Empirical: observations or measurements of actual events and, in some circumstances, underlying structures or mechanisms (Bhasker 1998).

The implication is that reality as seen at the level of the empirical appears more in observable terms, however because the observable character and nature of reality is a resultant influence of underlying generative mechanisms, it may well be that what is observed at the level of the empirical is a distorted representation of reality. The level of actual thus presents tendencies manifesting from these underlying relational mechanisms and to have a deep grasp of the nature of reality, it is necessary to unmask and unpack the underlying relational mechanisms that are in operation. Therefore, it is significant to peal the three domains of reality in order to understand the nature of racial tendencies which are often used to marginalise some racial groups within the schools' social context. So bringing CRT and CR together in this study meant that with CRT one attempted to put the nature of racial politics in education into critical perspective and expose how such operate. The use CR has sought to deconstruct the underlying mechanisms in order to differentiate between a disguised and hidden reality to that which is genuine. Therefore, the use of CRT and CR created a lens to problematize notions of racial exclusion and understand how it's been operationalised within the pedagogic milieu. 


\title{
3. Conceptualising Race
}

According to Richard Delgado (1998) race is a social construction. Delgado (1998: 193) define race as:

\begin{abstract}
As a vast group of people loosely bound together by historically contingent, socially significant elements of their morphology and/ancestry... race must be understood as a sui generis social phenomenon in which contested systems of meaning serve as the connections between physical features, faces and personal characteristics. In other words social meanings connect our faces to our souls. Race is neither an essence nor an illusion, but rather an ongoing, contradictory, self- reinforcing, plastic process subject to the macro forces of social and political struggle and the micro effects of daily decisions. The reference of terms like Black and white are social groups, not genetically distinct branches of humankind.
\end{abstract}

Social construction in the sense that, it means that which is derived rather from the social interactions and not from natural differentiation. Lopez (in Delgado 1994) sees the interactions as the source of human categorization and presupposes that this consequently leads to racial formation. Thus this dispels the conception that race is a genetically derived but support the social constructionist conceptualization of race. In South Africa race is more of a biological aspect but also social (Posel 2001). Different racial and ethnic groups interact at various levels of the society but retain their groupings according to a particular race or cultural ethnic group. The Department of Basic Education (DoBE) have since implemented policies that enhances inclusion of different races in schools and most schools have multi-racial classrooms and a mix of staff personnel from the four main population groups i.e. Blacks, Asians, Coloureds and Whites. It has always been a subject of debate if those who have been accommodated in previously privileged institution have been sufficiently included given the policy on inclusive education which derive most of its principles from the constitution of the country which condemns discrimination of whatever basis (RSA 1996). Furthermore the school governance structures of previously advantaged schools have not changed hence the whites still dominates the governance structures of such schools impacting on race and power relations (Karlsson 2002).

South Africa continue to experience racism in schools. The history of racism come a long way since the apartheid government introduced the policy of separate development according to racial groups. According to Vally and Dalamba (1999) in the report to the Commission of South African Human Rights, they postulate that segregation according to race in schools was instituted by the apartheid government in 1948. After the uprising in 1976 the Catholic Bishops conference began a movement to enroll black learners in catholic schools, the move that defied the government policies of the day. The enrollment of black leaners in white schools was further taken by private schools. Black learners were officially accepted in the so-called white schools in 1990 with conditions that white schools should maintain more than $50 \%$ majority of white learners, white cultural ethos and should continue to employ white teachers only. The financing of education was then left with parents and school governing councils. White schools were further proclaimed Model $\mathrm{C}$ schools with governing councils and principal being and the heart of their running. However twenty years down the line it is assumed that racial integration in schools has been achieved. Sourdien (2004) postulates that assimilation and not integration has occurred since the new democratic school dispensation as there have been an influx of learners to white schools but not from white schools to black schools. Furthermore white schools continue to operate like previously despite educational reforms resulting in the enculturation of black learners. While there is sometimes denial of the prevalence of racism in South African schools, the media is flooded with incidents of racial intolerance and hatred in schools. Studies analyzing media discourse like the one of De Wet (2001) found a strong presence of racism discourse in media reporting which to some extend provide evidence for the existence of racism in South African schools.

\section{Research Methodology}

The study was conducted qualitatively and interviews were conducted with ten selected Black-African learners who are attending school in five previously white advantaged secondary schools which had been racially integrated in the recent five years. Due to the sensitivity of the issue of race in schools, interviews were not conducted in a school setting, but learners were requested to participate in this study from their homes where they will feel free to share their experiences. Questions were open ended for learners to elaborate unhindered on their experiences. Data was collected using a voice recorder and thereafter were transcribed. An inductive analysis framework was used to analyse data. The following steps were followed in analysing data (see Laws, Harper \& Marcus, 2003, p. 395):

Step 1: Reading and re-reading of all the collected data: The purpose of reading the data closely was to ensure that I was fully conversant with the facts, thus making the process of analysis more manageable.

Step 2: Compiling a preliminary list of themes arising from the data and then expanding the list to make the 
process more manageable. correct.

Step 3: Re-reading the data again several times to confirm the themes and to verify that the interpretations were

Step 4: Linking the themes to quotations and notes: I jotted down themes alongside the quotations and notes as we went through the data.

Step 5: Perusing the categories of themes to interpret the data and answer the research questions.

Step 6: Designing a tool to assist the researcher in discerning patterns in the data. In order to triangulate and determine the patterns during the data analysis, a spreadsheet was used to give a summary of the themes. For example, the spreadsheet recorded the title of the theme and quotations from the different sets of data.

Step 7: Interpreting the data and deriving meaning: During this stage, I re-read the quotations and derived the meanings in relation to each of them. This resulted in my interpretations, which I presented according to each theme.

The two theoretical frameworks were used to understand the interpretations from the data. For instance with regard to CRT the following question was constantly asked "is race a factor here or not? "To unmask the generative mechanisms using CR the following question was asked: "what are the hidden factors influencing what is seen at the level of the empirical? And how are this played out as racial tendencies?

\section{Discussion of Findings}

The discussion of findings focuses on how well the data addressed the research question. The discussion of findings is presented according to the two research questions

5.1 Research question 1: To what extend does racial discrimination influence the implementation of inclusive education?

The following themes were derived from data:

\subsubsection{Theme 1: Race and identity formation}

Data revealed that race was still the basis from which learners determined their identity, for example when learners were asked about how they saw themselves within the school community. There was an indication that while these learners have been accommodated in this previously advantaged white schools they still formed their race identity based on their biological makeup, for example one learner said "we are learners of this school but you know that you are a Black or white we are not the same"

The implication is that apparently the categories of biological race are still prevalent despite efforts to create nonracial inclusive schools and consequently non-racial inclusive society.

\subsubsection{Theme 2: Racial tolerance}

The study has indicated while black learners have been included in the previously advantaged educational setting there was sporadic instances of non-tolerance between races. For example learners lamented that sometimes there is incidents where there is conflict between white and back learners with racial undertones. For example one learner said "if you are black, whites call you some names and likewise if you are white blacks call you sometimes, then you are made a laughing stock" This seem to indicate the prevalence of some level of intolerance from both races.

\subsubsection{Theme 3: Treatment from teachers}

It emerged from the analysis that in some instances the treatment of learners by their teachers was perceived by learners as based on which race they are. While learners acknowledged that their teachers treated them well there were indications that sometimes treatment showed preferential patterns depending on the race of the teacher. For instance one learner said "when we are in class, I see that white teacher likes white learners and a black teacher likes back learners, you see that when we answer questions white teachers choose many times white learners to answer"

Furthermore, it became evident that there existed suspicious or paranoid behaviour among the learners from different racial groups. For example asked if they trusted teachers and learners from other racial groups one of the learners alluded "I am worried that most whites get high marks in subjects taught by white teacher, you will see even in 
the prize giving function more white learners are receiving more awards than black learners"

\subsubsection{Theme 4: Academic performances}

The study revealed that there is a feeling that academic performances and subject choices were spread according to racial lines. That black learners did not do well in subjects like Physical Science and Mathematics, apparently because there seem to be a low expectation from the teachers that black learners cannot do these kind of subjects. For instance asked about the balance of numbers across subjects one learner said "in grade 10 most blacks are encouraged to do Mathematics Literacy as opposed to pure Mathematics" this was substantiated by the following extract from one learner "when you are chosen to do Mathematics you should be really good or else you are forced to do social sciences"

The study has shown that black learners suspected that marking assessments was biased and based on race, for example one learner cited "only certain learners get distinctions, we know it happens always". The implication of the above is that there seem to be a low expectation on part of black learners to do well especially in subjects like Mathematics and Physical Science which are perceived to be requiring a high level of intellectual functioning.

\subsubsection{Theme 5: Language of instruction versus the first language of the teacher}

The study showed that although English is the medium of instruction, teachers tended to use their mother-tongue when addressing learners who their mother-tongue is the same as theirs. For instance asked if teachers are consistent with the use of language to include all learners in their classes one of the learners alluded "well sometimes Afrikaans learners choose to ask questions in Afrikaans and the teachers whom Afrikaans is their mother-tongue will answer those learners in Afrikaans leaving the rest of us whom English is our language out of the conversation, I Usually feel left out when that happens"

The implication is that learners feel the use of different languages in a way exclude them from classroom conversations.

\subsubsection{Theme 6: School culture versus the family culture}

The study points out that usually the schools tend to identify with cultural practices which are reminiscent of the dominant racial group. For example one of the learners had this to say about the culture of their school "I think at our school more recognition is given to particular things which culturally white teachers find comfortable with, for example our school concert does not reflect what we as black students think we identify with"

\subsubsection{Theme 7: Management and administrative bias}

The study has found out that while learners feel part of the schools were they attend, there is however problem with the way some processes are handled especially when its issues pertaining to black learners. For instance one learner has this to say "when you get into a conflict with a white student, they are likely to get away with it because the management of the school is predominantly white, but if you as a black person you are found guilty, you could be suspended and sometimes expelled from school"

\subsection{Research question 2 how can racial integration be enhanced in South African schools?}

Based on the findings of research question 1 the following answers were generated to address the second research question:

\subsubsection{Theme 1: Race and identity formation}

Because it is clear from the study that race was still the basis from which learners formed their identities within the school community, schools will have to move away from race categorization of learners but rather focus on developing a colourblind school community by emphasizing the need to move beyond race. 


\subsubsection{Theme 2: Racial tolerance}

While it is sometimes difficult to deal with entrenched attitudes it is important to foster racial tolerance. Teachers should begin to be exemplary in ensuring that no racial bias is observed during their interaction with the learners. Being sarcastic about other races should be discouraged to both teachers and learners.

\subsubsection{Theme 3: Treatment from teachers}

Teachers have to act in a manner that is defensible beyond reasonable doubt. All learners must be subjected to the same treatment and that teachers needs to be open about how they treat learners, those from a race that is different from theirs. It is evident that what teachers do to other races could have replicating effect on how learners of the race similar to theirs could begin to emulate teachers and consequently result in the perpetuation of exclusive tendencies.

\subsubsection{Theme 4: Academic performances}

Teachers needs to ensure that the assessment criteria are clear to all learners and there needs to be transparency in the manner in which learners have obtained the scores. The score distribution should not exhibit a stereotype that only a particular race can do well. The choice of subjects should be based on merit and that all learners should be rewarded for their hard work regardless of race. To motivate all learners' teachers should have high expectations for all learners regardless of their race and motivate all learners alike.

\subsubsection{Theme 5: Language of instruction versus the first language of the teacher}

It is evident that the use mother-tongue of the teacher despite it not being the language of instruction in the presence of learners who cannot understand it could have exclusionary undertones. Therefore it is crucial to use the language that all learners can understand during educative interactions. Therefore in a South African school context for inclusion to succeed, the choice of language plays a pivotal role in making learners feel welcomed and included during the teaching and learning process.

\subsubsection{Theme 6: School culture versus the family culture}

Each and every school complete the incipient education the learner got from home. If there is inconsistency between family and school values, this has the potential to alienate learners. Schools should be careful not to enculturate the learners, rather the school should attempt to incorporate diversified values and cherish a multiculturalism. Teachers have to be sensitive of the cultural backgrounds of learners they teach in order to have a broader understanding of the implications of cultural diversity.

\subsubsection{Theme 7: Management and administrative bias}

Learners become aware if they are unfairly treated. The management of the school should pursue an administrative justice beyond all odds. They need to be transparent about how they deal with procedures so that there is consistency in the manner in which the rules are applied to all learners.

\section{Discussion}

The study has demonstrated that a racial integration has not been fully realized. That there is still racial intolerance in some schools. The study has shown that there is still a lack of trust based on racial preferential treatment which leads to suspicion among learners of different races. The non-transformed nature of school cultures perpetuates racial tendencies. There seem to be lack of consistency in terms of administrative justice which also contribute to suspicions about racial bias. While there experiences of the learners were analysed, a deeper analysis was made when I used CR analysis framework. The indication from the analysis is that the underlying cause of racial tendencies in school is to a great extent the racial attitudes emanating from the racial political system of the past while at the empirical level it appears as though that racial divisions have been resolved and in actual setting there is a lot of pretending that all is working well, the notion of the rainbow nation, the true nature of reality is that very little has shifted in terms of racial 
attitudes.

\section{Conclusion}

While it is difficult for South African to start talking about racial attitudes and tendencies which are inherently exclusive, schools are places that are better placed to begin a dialogue about the effects of racial attitudes, especially on the selfconcept and the scholastic performances of learners. While this article cannot claim to have resolved the problem of racial integration in schools because maybe only one race was interviewed, it however forms the basis for further research in enhancing racial integration in schools.

\section{References}

Bhaskar, R 1998, The possibility of naturalism, 3rd edn, Routledge, London.

Chisholm, L. \& Sujee, M. 2006. Tracking racial desegregation in South African schools. Journal of Education, no 40: 141-159.

Delgado, R \& Stefancic, J. 2006. Critical Race Theory: an introduction: NYU press www.nyupress.org. Retrieved 20/11/2013

Department of Education. 1997. Quality education for all: Overcoming barriers to learning and development. NCSNET and NCESS reports. Pretoria.

Department of Education. 2001. Education White Paper 6: Building an inclusive education and training and system. Pretoria: Government Printers.

Karlsson, J. 2002. The role of democratic governing bodies in South African schools. Comparative Education, 38(3), 327-336.

Kruger, N. 1998. Facilitating life skills. Lynnwood Ridge: Amabhuku.

Ladson-Billing, G 1998. Just what is critical race theory and what's it doing in a nice field like education. Qualitative Studies in Education, vol, 11, no, 1: 7-24.

Ladson-Billings, G.2009 Critical Race Theory in Education. International Handbook of Critical Education: Routledge: 110.

Ladson-Billing, G \& Tate iv, W.F. 1995. Towards a Critical Race Theory of Education. Columbia University, Teacher college, vol 97 no 1: 49-68.

Lopez, I.F.H in Delgado, R. 1994. Critical Race Theory: the cutting edge. Philadelphia: Temple University Press

Laws S, Harper C, \& Marcus R 2003. Research for Development. London: Sage.

Makoelle, T.M. 2012. The state of inclusive pedagogy in South Africa: A literature review. Journal of Sociology and Social Anthropology, 3(2):93-102.

Makoelle, T.M. 2013. Exploring teaching practices that are effective in promoting inclusion in South African secondary schools, Ph D thesis. Manchester: University of Manchester.

Posel, D. 2001. Race as common sense: racial classification in twentieth-century South Africa. African Studies Review, Vol. 44, No. 2 $87-113$

Republic of South Africa. 1996. The Constitution of the Republic of South Africa Act No. 108 of 1993. Pretoria: Government Printers.

Soudien, C. 2004. "Constituting the Class: An Analysis of the Process of 'Integration' in South African Schools. In Chisholm, L. (ed.) Education and Social Change in South Africa. Pretoria, HSRC Press.

Sowetan 2013. Malema: Racists must behave or else. Johannesburg: Sowetan, 06 June.

Vally, S \& Dalamba,Y. 1999. Racism, racial integration and segregation in South African public secondary schools. Johannesburg: South African Human Rights commission. 